\title{
Perencanaan Struktur Bawah dan Approach Jembatan Joyoboyo Surabaya, Jawa Timur
}

\author{
Indra Giri Angga Kusuma, Yudhi Lastiasih, Putu Tantri Kumala Sari \\ Departemen Teknik Sipil, Fakultas Teknik Sipil, Lingkungan, dan Kebumian, \\ Institut Teknologi Sepuluh Nopember (ITS) \\ E-mail: yudhi.lastiasih@gmail.com tantrigeoteknik@gmail.com
}

\begin{abstract}
Abstrak-Pemerintah Surabaya berencana membangun jembatan baru yang menghubungkan Jalan Raya Wonokromo ke bangunan Terminal Joyoboyo yang kelak akan berfungsi juga sebagai park and ride untuk angkutan masal cepat (trem). Jembatan baru yang direncanakan adalah Jembatan Joyoboyo. Jembatan Joyoboyo merupakan jembatan yang mempunyai dua jalur. Tiap jalur mempunyai 2 lajur dengan lebar lalu lintas $20 \mathrm{~m}$ yang terdiri dari lebar jalan $4 \mathrm{~m}$ dan bahu jalan $3 \mathrm{~m}$ pada tiap sisi. Jembatan ini dibangun diatas sungai Surabaya. Jembatan ini direncanakan memiliki panjang 130 meter dan menggunakan struktur utama berupa cable stay yang menumpu pada dua abutmen. Pada pangkal jembatan sisi kanan terdapat rencana oprit jembatan dengan timbunan tertinggi sebesar 3,5 meter. Jembatan ini dibangun di atas tanah dengan kedalaman tanah keras berada di kedalaman $16 \mathrm{~m}$. Kondisi tanah dasar dilapangan sangat mempengaruhi daya dukung tanah untuk menerima beban sehingga pada perencanaan struktur bawah dan approach jembatan ini perlu adaanya perencanaan yang tepat untuk menentukan alternatif perencanaan yang efektif dan efisien. Makalah kali ini membahas tentang perencanaan struktur bawah meliputi perencanaan abutmen dan pondasi tiang pancang serta akan menganalisa 2 alternatif perencanaan perkuatan tanah yaitu penggunaan geotextile wall dan penggunaan geogrid kombinasi dengan keystone-wall. Kemudian dari hasil analisa perhitungan perencanaan dinding penahan tanah didapatkan hasil bahwa perencanaan oprit menggunakan alternatif pertama memerlukan biaya material total sebesar $\mathrm{Rp} 755.234 .150,00$ dan untuk alternatif kedua memerlukan biaya material total sebesar Rp 721.376.150,00. Untuk perencanaan abutment direncanakan abutment dengan tinggi 4 meter dan pilecap berukuran 6 meter x 20 meter dan ditopang oleh 30 buah pondasi tiang pancang, dimana pondasi tiang pancang yang digunakan berdiameter $\mathbf{5 0}$ cm sedalam 27 m.
\end{abstract}

Kata Kunci-Abutment, Geogrid, Geotextile, Oprit, Keystone wall, Micropile.

\section{PENDAHULUAN}

K EMACETAN yang terjadi di Surabaya dengan berbagai penyebabnya, bermuara pada masalah orientasi transportasi masyarakat Surabaya Jumlah pengguna kendaraan pribadi di Surabaya tidak pernah berkurang, akan tetapi kendaraan pribadi ini tidak sebanding dengan penambahan atau pelebaran jalan baru di Surabaya. Pemerintah Kota Surabaya berusaha mengatasi permasalahan tersebut dengan mengembangkan transportasi berbasis angkutan massal cepat berupa trem. Salah satu sarana yang sedang disiapkan untuk mendukung konsep ini adalah mengubah bangunan Kantor Dishub Surabaya (Terminal Joyoboyo) menjadi park and ride baru atau tempat parkir kendaraan pribadi untuk menunjang angkutan massal cepat (AMC) berupa trem. Dengan adanya bangunan park and ride ini pemerintah Surabaya berencana membangun jembatan baru yang menghubungkan Jalan Raya Wonokromo ke bangunan Terminal Joyoboyo yang kelak akan berfungsi juga sebagai park and ride untuk angkutan masal cepat (trem).

Jembatan baru yang direncanakan adalah Jembatan Joyoboyo. Jembatan Joyoboyo merupakan jembatan yang mempunyai dua jalur. Tiap jalur mempunyai 2 lajur dengan lebar lalu lintas $20 \mathrm{~m}$ yang terdiri dari lebar jalan $3.5 \mathrm{~m}$ dan bahu jalan 1,5 m pada tiap sisi. Jembatan ini dibangun diatas sungai Surabaya seperti yang terlihat pada. Jembatan ini dengan panjang jembatan 100 meter dan menggunakan struktur utama berupa cable stay serta dipikul oleh dua abutmen dan pada pangkal jembatan sisi kanan terdapat rencana oprit jembatan dengan timbunan tertinggi sebesar 3,5. Jembatan ini dibangun di atas tanah dengan kedalaman tanah keras yang mencapai kedalaman 15 meter.

\section{TINJAUAN PUSTAKA}

\section{A. Tinjauan Umum}

Jembatan adalah suatu struktur kontruksi yang berfungsi untuk menghubungkan dua bagian jalan yang terputus oleh adanya rintangan-rintangan dan memungkinkan rute transportasi dapat melalui sungai, danau, kali, jalan raya, jalan kereta api dan lainlain. Pada umumnya suatu bangunan jembatan terdiri dari enam bagian pokok, yaitu: bangunan atas, landasan, bangunan bawah, pondasi, oprit, dan bangunan pengaman jembatan [1].

Oprit atau timbunan jalan pendekat jembatan adalah merupakan segmen sepanjang jalan yang dibatasi oleh lebar, tinggi tertentu sesuai alinyemen horizontal dan vertikal serta besarnya kelandaian melintang berdasarkan gambar rencana. Timbunan jalan pendekat sebagai pondasi dasar yang mendukung lapis pondasi bawah, bila lapis pondasi bawah tidak ada, maka lapisan tanah dasar mendukung langsung timbunan. Tinggi timbunan harus dipertimbangkan terhadap adanya bahaya longsor, sebaiknya pada lahan mencukupi dibuat kelandaian lereng alami dan apabila tidak mencukupi harus dibuat timbunan bersisi tegak dengan konstruksi penahan tanah.

\section{B. Perhitungan Tinggi Timbunan Awal ( $\left.H_{\text {Initial }}\right)$ dan} Timbunan Akhir $\left(H_{A k h i r}\right)$

Penentuan dari tinggi timbunan rencana pada saat pelaksanaan fisik (dengan memperhatikan adanya pemampatan), dapat dihitung dengan Persamaan.

Kondisi awal :

$$
q_{\text {awal }}=\mathrm{H}_{\text {initial }} \times \gamma_{\text {timbunan }}
$$

Setelah mengalami konsolidasi :

$$
q_{a k h i r}=\left(\mathrm{H}_{\text {initial }} \times \gamma_{\text {timb }}\right)-\left(\mathrm{Sc} \times\left(\gamma_{\text {timb }}-\gamma^{\prime}{ }_{\text {timb }}\right)\right)
$$

Untuk kondisi $\gamma_{\text {sat }} \neq \gamma_{\text {timb }}$ maka : 


$$
H_{\text {initial }}=\mathrm{q}+\left(\operatorname{Sc}\left(\gamma_{\text {timb- }} \gamma_{\text {timb }}^{\prime}\right)\right) / \gamma_{\text {timb }}
$$

Untuk kondisi $\gamma_{\text {sat }}=\gamma_{\text {timb }}$ maka :

$$
\begin{aligned}
& H_{\text {initial }}= \\
& H_{\text {akhir }}=\left(\mathrm{H}_{\text {initial }}-\mathrm{SC}_{\text {timb }}-\mathrm{S}_{\text {Pvmnt }}-\mathrm{H}_{\text {Bongkar }}\right)+\mathrm{H}_{\text {Pvmnt }}
\end{aligned}
$$

Dimana :

$\mathrm{q}_{\text {initial }}=$ beban yang diasumsi awal dalam perhitungan Sc sehingga didapat $\mathrm{H}_{\text {initial }}$ untuk perhitungan.

qakhir = beban akhir sebagai beban yang menyebabkan penurunan $\mathrm{H}_{\text {initial }}$ untuk mencapai $\mathrm{H}_{\text {final }}$ rencana.

$\mathrm{Sc}_{\text {timbunan }}=$ penurunan tanah dibawah timbunan oleh beban

$\mathrm{Sc}_{\text {Pavement }}=$ penurunan oleh akibat beban lalu lintas

$\mathrm{H}_{\text {bongkar }}=$ tinggi timbunan yang dapat dibongkar akibat pengaruh beban traffic

Sketsa perencanaan tinggi timbunan saat mengalami pemampatan digambarkan pada Gambar 1.

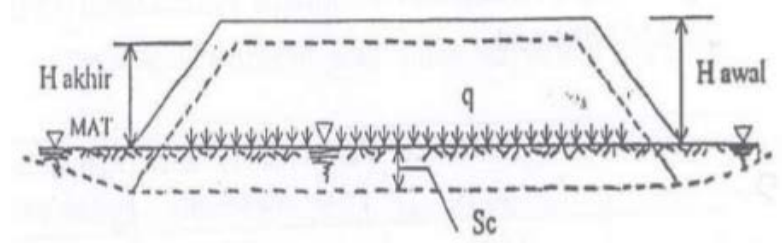

Gambar 1. Kedudukan timbunan saat mengalami pemampatan

\section{Pemampatan Tanah}

Pemampatan pada tanah dasar terjadi akibat diberikannya beban di atas tanah dasar tersebut yang menyebabkan deformasi partikel tanah serta mengecilnya pori-pori pada tanah tersebut akibat keluarnya air atau udara dari dalam pori. Dalam kasus perencanaan Jembatan Joyoboyo pemampatan terjadi akibat diberikan timbunan di atas tanah dasar yang dapat disebut pemampatan konsolidasi (Consolidation Settlement).

Pemampatan konsolidasi primer disebabkan oleh penimbunan timbunan setinggi $\mathrm{H}$ di atas tanah lunak yang akan menyebabkan terjadinya penambahan tegangan pada tanah dasar sehingga mengakibatkan adanya konsolidasi. Terdapat dua jenis konsolidasi berdasarkan tegangan yang diakibatkan, yaitu :

\section{1) Normally Consolidated Soil (NC-Soil)}

Tanah terkonsolidasi secara normal dimana tegangan overburden efektif pada saat ini merupakan tegangan maksimum yang pernah dialami tanah tersebut.

2) Over Consolidated Soil (OC-Soil)

Tanah terkonsolidasi lebih, di mana tegangan overburden efektif saat ini adalah lebih kecil daripada tegangan yang pernah dialami oleh tanah yang bersangkutan sebelumnya. Tanah disebut sebagai NC-Soil atau OC-soil tergantung dari harga Over Consolidation Ratio (OCR).

\section{Waktu Konsolidasi}

Menurut Terzaghi dalam Das (1985), lama waktu konsolidasi (t) dapat dihitung dengan Persamaan :

$$
t=\frac{T_{v}\left(H_{d r}\right)^{2}}{C_{v}}
$$

Dimana :

$\mathrm{t}=$ waktu konsolidasi

$\mathrm{T}_{\mathrm{v}}=$ time factor, bergantung dari derajat konsolidasi $\mathrm{U}(\%)$

$\mathrm{H}_{\mathrm{dr}}=$ jarak terjauh air pori dilapisan tanah mengalir keluar (m)

$\mathrm{C}_{\mathrm{v}}=$ koefisien konsolidasi akibat aliran air pori arah vertical

\section{E. Analisa Kestabilan Timbunan}

Untuk menganalisa kestabilan timbunan maka digunakan program bantu software PC. Software yang digunakan adalah
DXSTABLE. Parameter tanah (input) yang dibutuhkan pada program ini antara lain: $\gamma_{\text {sat }}, \gamma_{\mathrm{t}}, \mathrm{C}, \phi$, letak muka air tanah, koordinat permukaan tanah yang akan ditinjau dan koordinat segmen longsor yang akan ditinjau. Output yang dihasilkan antara lain: jari-jari bidang longsor, koordinat bidang longsor, angka keamanan (SF), dan momen penahan dari tanah.

\section{F. Metode Mempercepat Pemampatan dengan PVD (Prefabricated Vertical Drain)}

Pemampatan konsolidasi yang terjadi pada tanah lempung berlangsung sangat lambat. Oleh sebab itu untuk mempercepat terjadinya settlement $(\mathrm{U}=90 \%)$ dengan waktu efektif 6 bulan (24 minggu) perlu adanya pengurangan panjang jalur air pori. Ini dapat dilakukan dengan memasang Prefabricated Vertical Drain (PVD) di dalam tanah pada kedalaman dan jarak tertentu dengan formasi segitiga atau segiempat.

\section{G. Geotextile Wall Reinforcement}

Geosiynthesis yang paling banyak digunakan untuk perkuatan timbunan pada infrastruktur jalan dan oprit salah satunya adalah geotextile. Geotextile salah satu kegunaannya yaitu dapat digunakan untuk alternatif timbunan bersisi tegak. Pada perencanaannya perlu memperhatikan kekuatan tarik dari bahan dalam menerima dan memikul gaya geser saat terjadi kelongsoran. Pada perencanaan geotextile untuk timbunan bersisi tegak, ditinjau stabilitas pada :

1. Internal Stability

2. Overall Stability

Sehingga dapat ditentukan jumlah geotextile dan mutu geotextile yang memenuhi kedua syarat kestabilan tersebut.

\section{H. Geogrid Wall Reinforcement}

Secara umum geogrid adalah bahan geosynthetic yang berfungsi sebagai Perkuatan dan Stabilisasi, penjelasan berikut:

Pada perencanaan geogrid untuk timbunan bersisi tegak, ditinjau stabilitas pada :

1. Internal Stability

2. Overall Stability

Sehingga dapat ditentukan jumlah geogrid dan mutu geogrid yang memenuhi kedua syarat kestabilan tersebut.

\section{Perkuatan Tanah dengan Micropile.}

Mochtar, I.B., (2000) mengembangkan teori untuk konstruksi cerucuk / micropile dengan menggunakan asumsi bahwa :

1. Kelompok cerucuk dianggap sebagai kelompok tiang dengan "rigid cap" di muka tanah yang menerima gaya horizontal.

2. Gaya horizontal tersebut merupakan tegangan geser yang terjadi sepanjang bidang gelincir. Seperti digambarkan pada Gambar 2.3 sebagai berikut :

\section{J. $\quad$ Retaining Wall Reinforment Type Keystone Wall}

Keystone wall yang digunakan sebagai dinding penahan tanah segmental adalah Keystone wall dengan tipe Keystone Compac IV (Straight - Face). Keystone wall yang direncanakan tidak menerima gaya horisontal dari timbunan tanah karena semua gaya horizontal telah diterima oleh geogrid.

\section{K. Perencanaan Abutment}

Dalam perencanaan abutment perencanaan beban yang bekerja pada sturktur bangunan bawah jembatan berdasarkan 
pada SNI 1725:2016 dan SNI 2833-2008. Dimana beban yang bekerja di kombinasikan untuk menghasilkan nilai beban seperti kondisi kenyataannya.

Ilustrasi beban yang bekerja pada abutment seperti Gambar 2 sebagai berikut :

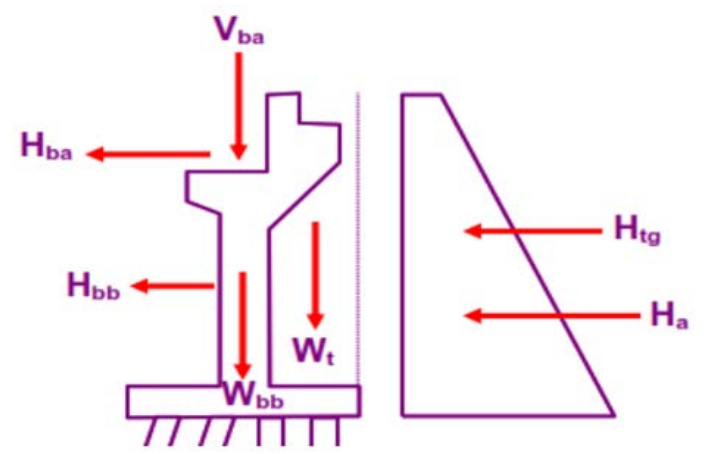

Gambar 2. Ilustrasi Beban yang Bekerja pada Abutment

\section{Stabilitas pada Abutment}

Stabilitas abutment dapat ditentukan dengan menganalisa berbagai kestabilan sebagai berikut :

a. Kontrol terhadap bahaya geser

b. Kontrol terhadap bahaya ambles

c. Kontrol overall stability

\section{Perencanaan Tiang Pancang}

Tiang pancang dengan jumlah tiang lebih dari satu maka bila dipasang dengan spasi antar tiang 2 - 2,5D maka tiang tersebut menjadi tiang group sehingga harus ada factor efisiensi. Faktor efisiensi tersebut dapat ditentukan menggunakan persamaan berikut :

$$
C=1-\arctan \frac{D}{S} \times\left[\frac{(n-1) \times m+(m-1) \times n}{90 \times m \times n}\right]
$$

Dimana:

$\mathrm{C}=$ faktor reduksi

$\mathrm{D}=$ diameter tiang pancang

$\mathrm{S}=$ jarak antara pusat tiang pancang

$\mathrm{m}=$ jumlah baris dalam kelompok tiang pancang

$\mathrm{n}=$ jumlah tiang pancang dalam satu baris

Secara umum perumusan kapasitas daya dukung tiang pancang dapat dirumuskan :

$$
Q_{u l t}=Q s+Q p
$$

Dimana:

$\mathrm{Qult}_{\text {u }}$ Daya dukung ultimate pondasi tiang pancang

Qs = Gesekan sepanjang keliling tiang pancang (friction).

$\mathrm{Qp}$ = Daya dukung ujung tiang pancang (end bearing capacity).

\section{METODOLOGI}

Langkah langkah pengerjaan tugas akhir ini dijelaskan dalam diagram alir pada Gambar 3.

\section{ANALISA DATA}

\section{A. Pengumpulan Data dan Analisa}

Timbunan direncanakan bersisi tegak dengan tinggi final sesuai dengan elevasi pada oprit tertinggi yaitu $\mathrm{H}=3.500 \mathrm{~m}$, lebar timbunan $\mathrm{L}=20 \mathrm{~m}$ dengan Sifat fisik timbunan meliputi:

$\begin{array}{ll}\text { Jenis Tanah } & : \text { Pasir Sirtu } \\ \gamma_{\mathrm{t}} & : 1.8 \mathrm{t} / \mathrm{m}^{3}, \\ \phi & : 30^{0} \\ \mathrm{Cu} & : 0\end{array}$

Untuk data tanah dasarnya direkap dalam Tabel 1

\section{B. Data Spesifikasi Bahan}

1) Geotextille

Geotextile yang digunakan dalam alternatif perkuatan timbunan adalah woven geotextille tipe 200/45 yang memiliki ultimate strength sebesar $200 \mathrm{kN} / \mathrm{m}$ dari produk Geotech Stabilenka. Brosur spesifikasi produk dapat dilihat pada lampiran

\section{2) Geogrid}

Geogrid yang digunakan dalam alternatif perkuatan timbunan perencanaan oprit bersisi tegak adalah tipe UniAxial Grids Tenax TT 160 SAMP yang memiliki ultimate strength sebesar $160 \mathrm{kN} / \mathrm{m}$ dari produk PT. Teknindo Geosistem Unggul. Brosur spesifikasi produk disajikan pada lampiran.

3) Micropile

Micropile berupa minipile concrete yang digunakan sebagai perkuatan timbunan bersisi tegak terhadap kontrol ambles adalah minipile prestressed square pile dari produk waskita precast. Brosur ukuran dan spesifikasi produk disajikan pada lampiran.

4) Keystone Wall

Keystone Wall yang digunakan dalam alternatif perencanaan dinding samping orprit bersisi tegak adalah produk keystone compact IV dengan berat $34 \mathrm{~kg} / \mathrm{unit}$. Brosur produk disajikan pada lampiran

\section{5) Pondasi Tiang Pancang}

Pondasi Tiang pancang pada perencanaan pondasi dalam abutment direncanakan menggunakan produk waskita Precast tipe Pc Spun Pile. Brosur produk disajikan pada lampiran

6) Prefabricated Vertical Drain (PVD) \& Prefabricated Horizontal Drain (PHD)

PVD yang digunakan berfungsi untuk mempercepat terjadinya settlement ( $\mathrm{U}=90 \%$ ) dengan waktu efektif 6 bulan. PHD berfungsi untuk mengalirkan air dari PVD sampai ke drainase samping oprit. Digunakan produk Geoforce Indonesia tipe GD-90. Brosur Produk disajikan pada lampiran. 


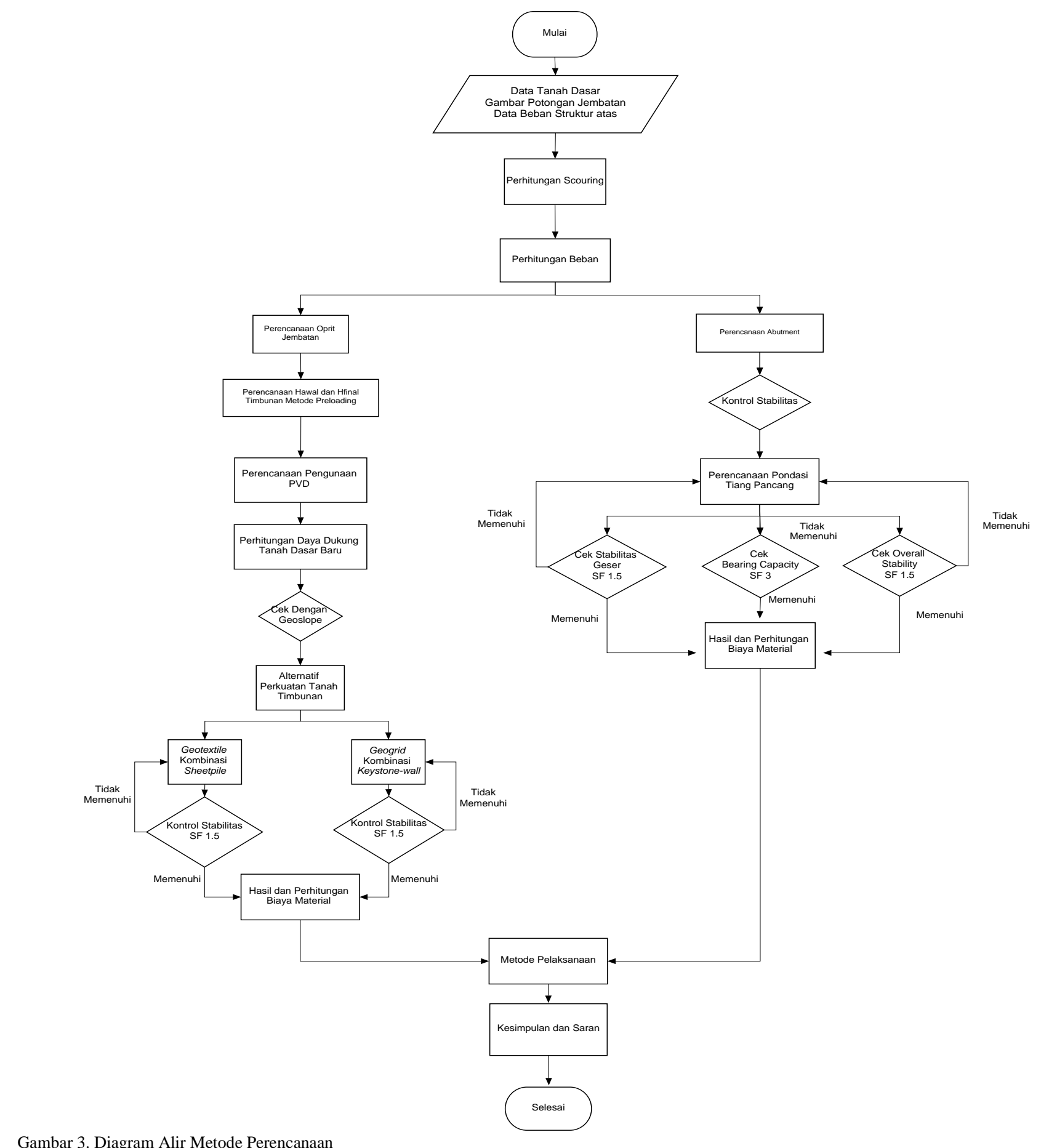

Gambar 3. Diagram Alir Metode Perencanaan

Tabel 1.

Data Tanah

\begin{tabular}{|c|c|c|c|c|c|c|c|c|c|c|c|c|c|c|c|}
\hline $\begin{array}{c}\text { Kedalaman } \\
\text { (m) }\end{array}$ & $\begin{array}{c}\text { Average } \\
\text { Nilai Nspt }\end{array}$ & Deskripsi & $\begin{array}{l}\text { Konsistensi } \\
\text { Jenis Tanah }\end{array}$ & $\begin{array}{l}\text { Wc } \\
\%\end{array}$ & $\begin{array}{c}\text { Gs } \\
\mathrm{gr} / \mathrm{cm}^{3}\end{array}$ & $\begin{array}{l}\gamma \mathbf{s a t} \\
\mathbf{t} / \mathbf{m}^{3}\end{array}$ & $\begin{array}{l}\gamma d \\
t / \mathbf{m}^{3}\end{array}$ & $\begin{array}{c}\gamma t \\
\mathbf{t} / \mathbf{m}^{3}\end{array}$ & $\begin{array}{c}\mathbf{L L} \\
\%\end{array}$ & $\begin{array}{l}\text { PI } \\
\%\end{array}$ & $\begin{array}{c}\text { Cu } \\
\text { Kpa }\end{array}$ & eo & Cc & Cs & $\begin{array}{c}\text { CV } \\
\mathrm{cm}^{2} / \text { det }\end{array}$ \\
\hline $0-1$ & 4 & $\begin{array}{c}\text { Lempung } \\
\text { Lanau } \\
\text { Berpasir }\end{array}$ & Soft & 79,38 & 2,564 & 1,600 & 0,953 & 1,600 & 64,45 & 34,010 & 7,78 & 2,144 & 0,901 & 0,195 & 0,00042 \\
\hline $1-3$ & 7 & $\begin{array}{l}\text { Lempung } \\
\text { Lanau } \\
\text { Berpasir }\end{array}$ & Medium & 68,85 & 2,564 & 1,650 & 1,032 & 1,650 & 64,45 & 34,010 & 9,06 & 1,859 & 0,745 & 0,164 & 0,00050 \\
\hline $3-8$ & 1 & $\begin{array}{c}\text { Lempung } \\
\text { Lanau } \\
\text { Berpasir }\end{array}$ & Very Soft & 89,91 & 2,564 & 1,550 & 0,874 & 1,550 & 64,45 & 34,010 & 11,81 & 2,428 & 1,080 & 0,231 & 0,00033 \\
\hline $8-15$ & 9 & $\begin{array}{l}\text { Lempung } \\
\text { Berpasir }\end{array}$ & Medium & 61,83 & 2,564 & 1,683 & 1,085 & 1,683 & 63,82 & 34,470 & 16,87 & 1,415 & 0,649 & 0,144 & 0,00056 \\
\hline
\end{tabular}




\begin{tabular}{|c|c|c|c|c|c|c|c|c|c|c|c|c|c|c|c|}
\hline $15-19$ & 15 & $\begin{array}{l}\text { Lempung } \\
\text { Berpasir }\end{array}$ & Stiff & 61,83 & 2,667 & 1,735 & 1,176 & 1,735 & 63,82 & 34,470 & 43,00 & 1,270 & 0,433 & 0,101 & 0,00056 \\
\hline $19-27$ & 29 & $\begin{array}{c}\text { Lempung } \\
\text { Berpasir }\end{array}$ & Very Stiff & 47,51 & 2,645 & 1,735 & 1,176 & 1,735 & 68,77 & 36,360 & 124,00 & 1,230 & 0,301 & 0,075 & 0,07451 \\
\hline $27-29$ & 44 & $\begin{array}{c}\text { Lempung } \\
\text { Berpasir }\end{array}$ & Hard & 46,65 & 2,645 & 1,735 & 1,184 & 1,735 & 68,77 & 36,360 & 124,00 & 1,230 & 0,336 & 0,084 & 0,08441 \\
\hline $29-30$ & 38 & $\begin{array}{l}\text { Lempung } \\
\text { Berpasir }\end{array}$ & Very Stiff & 43,81 & 2,732 & 1,788 & 1,244 & 1,788 & 64,75 & 33,500 & 155,00 & 1,200 & 0,308 & 0,076 & 0,07637 \\
\hline
\end{tabular}

Tabel 2.

Hasil Running DXSTABLE

\begin{tabular}{cccccccc}
\hline \hline \multirow{2}{*}{ No. } & \multirow{2}{*}{ SF (bishop) } & Moment resisting (KN-m) & \multicolumn{2}{c}{ Circle center } & Radius & Initial & Terminal \\
\cline { 3 - 7 } & & $\mathbf{x}(\mathbf{m})$ & $\mathbf{y ~ ( m )}$ & $\mathbf{m}$ & $\mathbf{x ~ ( m )}$ & $\mathbf{x ~ ( m ) ~}$ \\
\hline 1 & 0,964 & 1050 & 19,45 & 19,12 & 6,340 & 14,630 & 25.76 \\
2 & 0,965 & 1057 & 19,5 & 19,13 & 6,350 & 14,670 & 25,82 \\
3 & 0,966 & 1062 & 19,51 & 19,14 & 6,370 & 14,670 & 25,85 \\
4 & 0,968 & 1129 & 19,50 & 19,29 & 6,590 & 14,500 & 26,03 \\
5 & 0,969 & 1166 & 19,57 & 19,38 & 6,700 & 14,500 & 26,21 \\
\hline \hline
\end{tabular}

\section{PEMBAHASAN}

\section{A. Perhitungan Pemampatan dan Tinggi Awal $\left(H_{\text {initial }}\right)$}

Dalam perhitungan $\mathrm{H}_{\text {initial }}$ dan $\mathrm{H}_{\text {final, pemampatan tanah }}$ dasar yang diperhitungkan adalah yang masih bisa mengalami proses konsolidasi primer atau setebal lapisan compressible $(\mathrm{H})$ dengan konsistensi tanah dasar very soft soil s/d medium soil. Perhitungan besar pemampatan dilakukan untuk mencari tinggi timbunan awal yang dibutuhkan untuk mencapai tinggi rencana ketinggian oprit

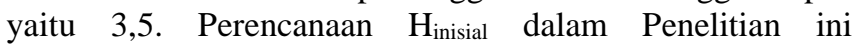
memperhitungkan beban timbunan, beban traffic, dan beban perkerasan dengan hasil grafik perhitungan digambarkan pada Gambar 4 dan 5.

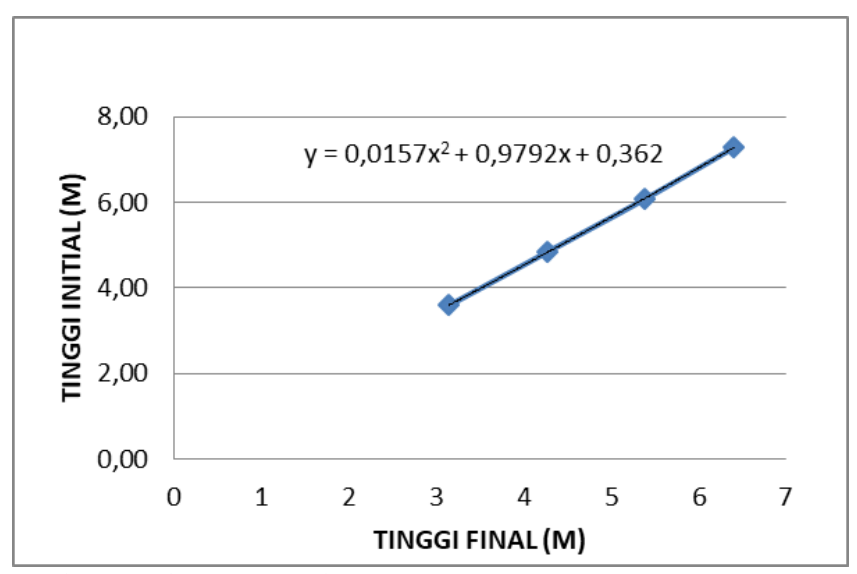

Gambar 4. Hubungan $\mathrm{H}_{\text {final }}$ dengan $\mathrm{H}_{\text {initial }}$

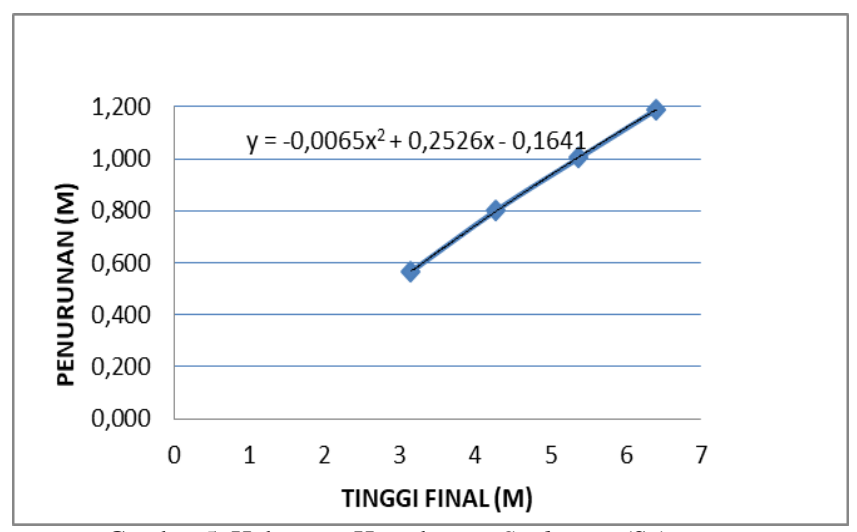

Gambar 5. Hubungan $\mathrm{H}_{\text {final }}$ dengan Settlement (Sc)
Berdasarkan Gambar 4 dan 5 maka untuk $\mathrm{H}_{\text {final }}=3,5$ meter dapat ditentukan $\mathrm{H}_{\text {initial }}$ yang tejadi adalah sebesar 3,982 meter dengan settlement sebesar 0,64 meter.

\section{B. Perbaikan Tanah Dasar}

Waktu konsolidasi alami yang terjadi cukup lama yaitu hingga 134 tahun, sehingga diperlukan Prefabricated Vertical Drain (PVD) untuk mempercepat waktu konsolidasi.

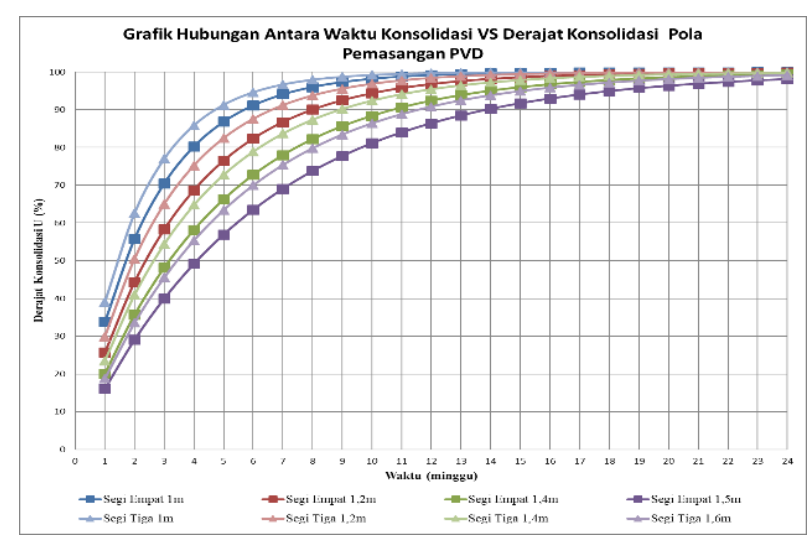

Gambar 6. Grafik Hubungan Waktu dengan Derajat Konsolidasi (U) dengan menggunakan PVD Pola Segiempat dan Segi empat

PVD yang digunakan dalam perencanaan adalah menggunakan pola segitiga dengan jarak antar PVD adalah 0,9 m. karena Area serap pola segitiga lebih luas dibandingkan dengan segi empat dan jarak spasi antar PVD yang digunakan adalah $\mathrm{S}=0,9$ meter atas pertimbangan dapat mencapai $\mathrm{U}=90 \%$ dalam waktu 8 minggu pentahapan penimbunan. yang lain adalah mahalnya harga material PVD.

\section{Stabilitas Timbunan}

Setelah menghitung perbaikan tanah menggunakan PVD kemudian dilakukan kontrol overall stability dan internal stability menggunakan software DXSTABLE untuk mengetahui nilai safety factor (SF). Dilakukan perhitungan SF sebanyak 5 kali untuk timbunan tegak dengan $\mathrm{H}_{\text {initial }}$ 3,982. Hasil Running dengan 5 nilai minimum hasil kontrol overall stability ditabelkan sebagai Pada Tabel 2.

Dari perhitungan SF diatas didapatkan bahwa SF terkecil hasil kontrol adalah sebesar 0,964 dimana nilai SF ini masih kurang dari SF rencana sebesar 1,25 maka stabilitas timbunan dianggap tidak aman, sehingga dibutuhkan perkuatan untuk kestabilan timbunan. 


\section{Perencanaan Geotextile Walls sebagai Perkuatan Oprit} Timbunan (Alternatif 1)

Adalapun hasil perhitungan kebutuhan geotextile pada $\mathrm{H}_{\text {initial }}$ oprit 3,982 m yang ditabelkan pada Tabel 3 dan 4 .

Berikut Sketsa pemasangan geotextile wall yang telah diperhitungkan :

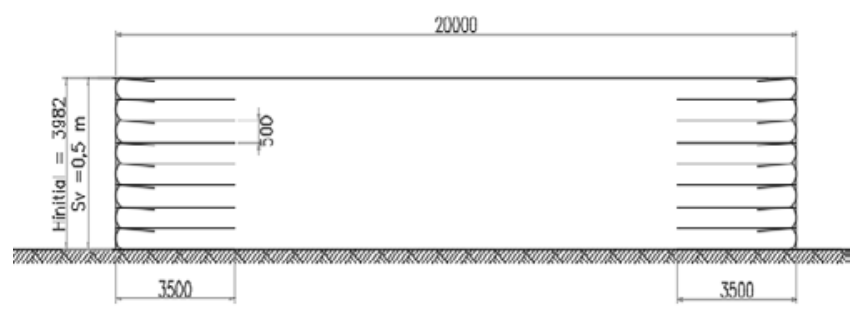

Gambar 7. Sketsa pemasangan geotextile wall.

E. Perencanaan Geogrid kombinasi Keystone-wall sebagai Perkuatan Oprit Timbunan (Alternatif 2)

Adapaun hasil perhitungan kebutuhan geogrid pada Hinitial oprit 3,982 m yang ditabelkan pada Tabel 5 dan 6 .

Berikut Sketsa pemasangan geogrid wall yang telah diperhitungkan :

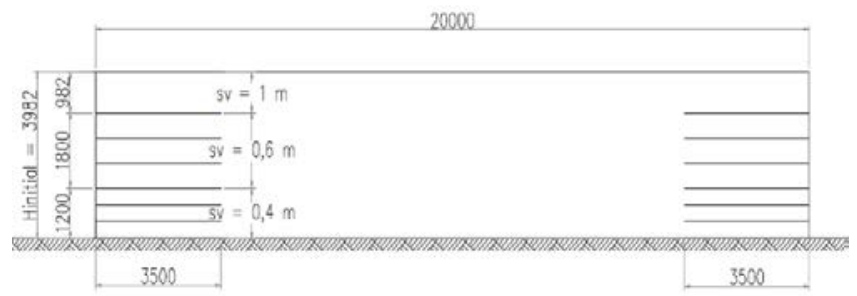

Gambar 8. Sketsa pemasangan geogrid wall.

- Perencanaan Keystone-wall

Keystone wall yang digunakan sebagai dinding penahan tanah segmental adalah Keystone wall dengan tipe Keystone
Compac IV (Straight - FaceSketsa pemasangan keystonewall digambarkan pada Gambar 9.

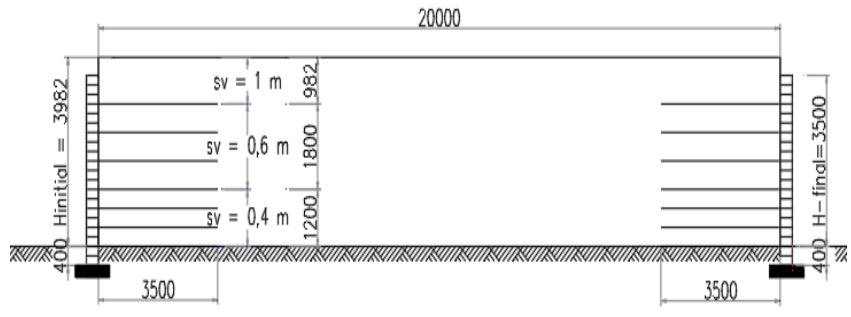

Gambar 9. Sketsa pemasangan keystone

\section{F. Perencanaan Micropile Sebagai Perkuatan Bearing Capacity}

Micropile dalam tugas akhir ini digunakan untuk perkuatan timbunan agar tidak mengalami bearing capacity failure diakrenakan hasil perhitungan stabilitas bearing capacity failure dari 2 alternatif perkuatan belum memenuhi. Jumlah micropile yang telah diperhitungkan guna memenuhi SF 1,5 digunakan 11 buah micropile untuk kedua sisi timbunan dengan sketsa pemasangan Micropile digambar pada Gambar 10.

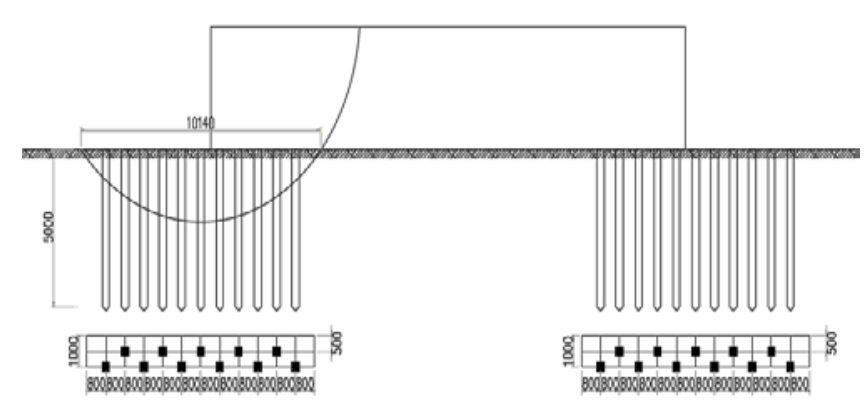

Gambar 10. Sketsa pemasangan micropile

Tabel 3.

Sv Pemasangan Geotextile

\begin{tabular}{ccccccccc}
\hline \hline $\mathbf{Z}(\mathbf{m})$ & Ka timb & $\boldsymbol{\gamma ( \mathbf { t } / \mathbf { m } ^ { \mathbf { 3 } } )}$ & $\boldsymbol{\sigma} \mathbf{H s}\left(\mathbf{t} / \mathbf{m}^{\mathbf{2}}\right)$ & $\boldsymbol{\sigma} \mathbf{H q}\left(\mathbf{t} / \mathbf{m}^{2}\right)$ & $\sum \boldsymbol{\sigma H}\left(\mathbf{t} / \mathbf{m}^{2}\right)$ & $\mathbf{T}$ allow $(\mathbf{t} / \mathbf{m})$ & $\mathbf{S v}(\mathbf{m})$ & Sv pakai $(\mathbf{m})$ \\
\hline 0 & 0,333 & 1,8 & 0 & 0,5 & 0,5 & & & \\
1 & 0,333 & 1,8 & 0,6 & 0,5 & 1,1 & 3,092 & 187,381 & 0,5 \\
2 & 0,333 & 1,8 & 1,2 & 0,5 & 1,7 & 3,092 & 121,247 & 0,5 \\
3 & 0,333 & 1,8 & 1,8 & 0,5 & 2,3 & 3,092 & 0,89617 & 0,5 \\
3,9 & 0,333 & 1,8 & 2,34 & 0,5 & 2,8 & 3,092 & 0,72577 & 0,5 \\
\hline \hline
\end{tabular}

Tabel 4.

Le,Lr, dan Lo geotextile

\begin{tabular}{cccccccccc}
\hline \hline \multirow{2}{*}{$\mathbf{Z}(\mathbf{m})$} & \multirow{2}{*}{ Ka timb } & \multirow{2}{*}{$\boldsymbol{\gamma}\left(\mathbf{t} / \mathbf{m}^{\mathbf{3}}\right)$} & \multirow{2}{*}{$\boldsymbol{\sigma} \mathbf{v}\left(\mathbf{t} / \mathbf{m}^{2}\right)$} & \multicolumn{3}{c}{ Hitungan } & \multicolumn{2}{c}{ Pakai } & \multirow{2}{*}{ Keterangan } \\
\cline { 6 - 8 } & & & & $\mathbf{L e}(\mathbf{m})$ & $\mathbf{L r}(\mathbf{m})$ & $\mathbf{L o}(\mathbf{m})$ & $\mathbf{L e} \& \mathbf{L r}(\mathbf{m})$ & $\mathbf{L o}(\mathbf{m})$ & \\
\hline 0 & 0,333 & 1,8 & & & & & & & \\
1 & 0,333 & 1,8 & 1,8 & 0,200 & 1,721 & 0,198 & 3,5 & 1 & tidak menerus \\
2 & 0,333 & 1,8 & 3,6 & 0,234 & 1,144 & 0,153 & 3,5 & 1 & tidak menerus \\
3 & 0,333 & 1,8 & 5,4 & 0,255 & 0,567 & 0,138 & 3,5 & 1 & tidak menerus \\
3,9 & 0,333 & 1,8 & 7,02 & 0,269 & 0,047 & 0,131 & 3,5 & 1 & tidak menerus \\
\hline \hline
\end{tabular}

Tabel 5.

Sv Pemasangan Geogrid

\begin{tabular}{ccccccccc}
\hline \hline $\mathbf{Z}(\mathbf{m})$ & Ka timb & $\boldsymbol{\gamma}\left(\mathbf{t} / \mathbf{m}^{\mathbf{3}}\right)$ & $\boldsymbol{\sigma} \mathbf{H s}\left(\mathbf{t} / \mathbf{m}^{2}\right)$ & $\boldsymbol{\sigma} \mathbf{H q}\left(\mathbf{t} / \mathbf{m}^{2}\right)$ & $\sum \boldsymbol{\sigma H}\left(\mathbf{t} / \mathbf{m}^{2}\right)$ & $\mathbf{T}$ allow $(\mathbf{t} / \mathbf{m})$ & Sv (m) & Sv pakai (m) \\
\hline 0 & 0,333333 & 1,8 & 0 & 0,5 & 0,5 & & & \\
1 & 0,333333 & 1,8 & 0,6 & 0,5 & 1,1 & 2,473 & 149,905 & 1 \\
2 & 0,333333 & 1,8 & 1,2 & 0,5 & 1,7 & 2,473 & 0,96997 & 0,6 \\
3 & 0,333333 & 1,8 & 1,8 & 0,5 & 2,3 & 2,473 & 0,71694 & 0,6 \\
3,9 & 0,333333 & 1,8 & 2,34 & 0,5 & 2,84 & 2,473 & 0,58062 & 0,4 \\
\hline \hline
\end{tabular}


Tabel 6.

Le dan Lr, geogrid

\begin{tabular}{|c|c|c|c|c|c|c|c|}
\hline \multirow{2}{*}{$\mathrm{Z}(\mathrm{m})$} & \multirow{2}{*}{ Ka timb } & \multirow{2}{*}{$\gamma\left(\mathbf{t} / \mathbf{m}^{3}\right)$} & \multirow{2}{*}{$\sigma \mathrm{v}\left(\mathrm{t} / \mathrm{m}^{2}\right)$} & \multicolumn{2}{|c|}{ Hitungan } & \multirow{2}{*}{$\begin{array}{c}\text { Pakai } \\
\text { Le \& Lr (m) }\end{array}$} & \multirow{2}{*}{ Keterangan } \\
\hline & & & & Le (m) & $\operatorname{Lr}(\mathrm{m})$ & & \\
\hline 0 & 0,333333 & 1,8 & & & & & \\
\hline 1 & 0,333333 & 1,8 & 1,8 & 0,33679 & 1,72138 & 3,5 & tidak menerus \\
\hline 2 & 0,333333 & 1,8 & 3,6 & 0,21927 & 1,14403 & 3,5 & tidak menerus \\
\hline 3 & 0,333333 & 1,8 & 5,4 & 0,22858 & 0,56668 & 3,5 & tidak menerus \\
\hline 3,9 & 0,333333 & 1,8 & 7,02 & 0,15595 & 0,04707 & 3,5 & tidak menerus \\
\hline
\end{tabular}

Tabel 7.

Biaya Material Alternatif Geotextile wall

\begin{tabular}{|c|c|c|c|c|c|}
\hline No & Jenis Pekerjaan & Satuan & Volume & Harga per $\left(\mathrm{m}^{3}\right)$ & Total Harga (+PPN 10\%) \\
\hline 1 & Timbunan & $\mathrm{m} 3$ & 3654 & Rp 93.750,00 & Rp 376.818.750,00 \\
\hline 2 & Geotextile & $\mathrm{m} 2$ & 3036 & Rp 18.000,00 & Rp 60.112.800,00 \\
\hline 3 & Keystone wall & $\mathrm{m} 2$ & 526 & Rp 550.000,00 & Rp 318.302.600,00 \\
\hline \multicolumn{5}{|c|}{ Total Harga } & Rp 755.234.150,00 \\
\hline
\end{tabular}

Tabel 8.

Biaya Material Alternatif Geogrids dan Keystone-wall

\begin{tabular}{cccccc}
\hline \hline No & Jenis Pekerjaan & & Volume & Harga per $\left.\mathbf{( m}^{\mathbf{3}}\right)$ & Total Harga (+PPN 10\%) \\
\hline 1 & Timbunan & $\mathrm{m} 3$ & 3654 & Rp 93.750,00 & Rp 376.818.750,00 \\
2 & Geogrid & $\mathrm{m} 2$ & 1836 & Rp 13.000,00 & Rp 26.254.800,00 \\
3 & Keystone wall & $\mathrm{m} 2$ & 526 & Rp 550.000,00 & Rp 318.302.600,00 \\
& & & Rp 721.376.150,00 \\
\hline \hline
\end{tabular}

Tabel 9.

Rekap Total Kombinasi Pembebanan

\begin{tabular}{cccccc}
\hline \hline \multirow{2}{*}{ Kombinasi Pembebanan } & \multicolumn{3}{c}{ Gaya (ton) } & momen-x & momen-y \\
\cline { 2 - 6 } & $\mathbf{H x}$ & Hy & $\mathbf{V}$ & $\mathbf{( t - m )}$ & $\mathbf{( t - m )}$ \\
\hline Kombinasi 1 & 210,77 & 0,00 & 2548,16 & 0,00 & 32,17 \\
Kombinasi 2 & 212,94 & 0,00 & 2548,16 & 0,00 & 36,61 \\
Kombinasi 3 & 210,77 & 1,05 & 2548,16 & 3,34 & 32,17 \\
Kombinasi 4 & 212,94 & 1,05 & 2548,16 & 3,34 & 36,61 \\
Kombinasi 5 X & 913,65 & 156,56 & 2277,28 & 298,79 & 1247,14 \\
Kombinasi 5 Y & 386,64 & 521,88 & 2277,28 & 995,97 & 190,16 \\
\hline \hline
\end{tabular}

\section{G. Analisa Biaya Material}

Hasil perhitungan total biaya alternatif perkuatan timbunan Geotextile wall dan biaya alternatif perkuatan timbunan kombinasi Geogrids dan Keystone-waldapat dilihat pada Tabel 7 dan Tabel 8.

\section{H. Perencanaan Abutment}

Data Perencanaan :

Panjang girder (L)

Lebar jalan (b)

Lebar Trotoar

$=30 \mathrm{~m}$

Tebal plat lantai jembatan $\left(\mathrm{t}_{\mathrm{s}}\right)$

Tebal lapisan aspal + overlay $\left(\mathrm{t}_{\mathrm{a}}\right)$

Lebar abutment (B)

Tinggi abutment (ha)

Dengan gambar sketsa perencanaan digambarkan pada Gambar 11.

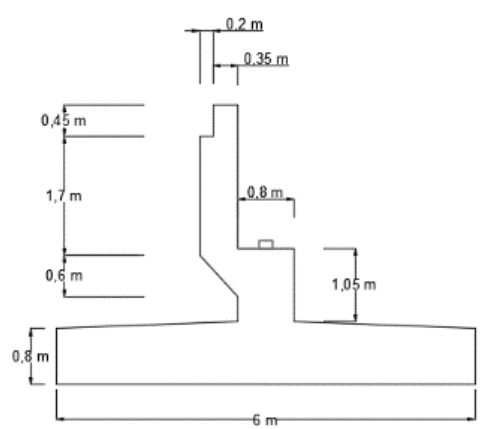

Rekap Kombinasi Beban yang terjadi di abument ditabelkan pada Tabel 9 berikut ini :

Tabel 9.

Rekap Total Kombinasi Pembebanan

\begin{tabular}{cccccc}
\hline \hline \multirow{2}{*}{$\begin{array}{c}\text { Kombinasi } \\
\text { Pembebanan }\end{array}$} & \multicolumn{3}{c}{ Gaya (ton) } & \multicolumn{3}{c}{ momen-x } & momen-y \\
\cline { 2 - 6 } & Hy & V & (t-m) & (t-m) \\
\hline Kombinasi 1 & 210,77 & 0,00 & 2548,16 & 0,00 & 32,17 \\
Kombinasi 2 & 212,94 & 0,00 & 2548,16 & 0,00 & 36,61 \\
Kombinasi 3 & 210,77 & 1,05 & 2548,16 & 3,34 & 32,17 \\
Kombinasi 4 & 212,94 & 1,05 & 2548,16 & 3,34 & 36,61 \\
Kombinasi 5 X & 913,65 & 156,56 & 2277,28 & 298,79 & 1247,14 \\
Kombinasi 5 Y & 386,64 & 521,88 & 2277,28 & 995,97 & 190,16 \\
\hline \hline
\end{tabular}

\section{Perencanaan Tiang Pancang}

Dalam perencanaan ini digunakan tiang pancang PC spun pile (Waskita precast) grade $\mathrm{C}$, dengan spesifikasi sebagai berikut:

Mutu beton, fc' $\quad=60 \mathrm{MPa}$

Outside Diameter $\quad=500 \mathrm{~mm}$

Wall thickness $\quad=90 \mathrm{~mm}$

Class $\quad=\mathrm{C}$

AP $\quad=1159 \mathrm{~cm}^{2}$

Allowable axial $\quad=169$ ton

Bending moment (crack) $\quad=17 \mathrm{t} . \mathrm{m}$

Bending moment (ultimate) $\quad=34 \mathrm{t} . \mathrm{m}$

Kedalaman tanam tiang rencana, $(\mathrm{Ld}) \quad=27 \mathrm{~m}$

Dengan gambar sketsa group tiang pancang yang direncanakan digambarkan pada Gambar 12. 


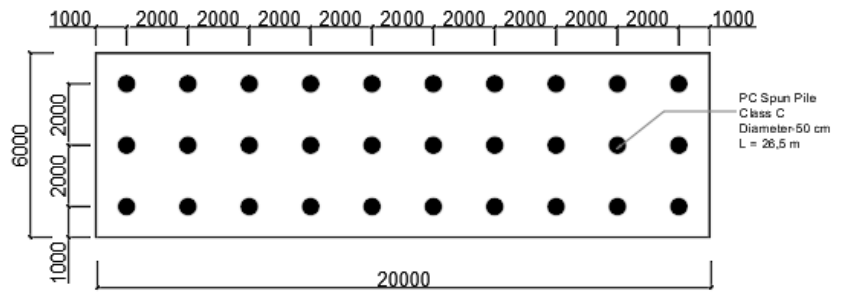

Gambar 12. Konfigurasi Tiang Pancang Abutment

Kemudian tiang pancang dikontol dengan hasil kontrol sebagai berikut :

- Kontrol Terhadap Gaya Vertikal Tiang

Tabel 10.

Kontrol Tegangan Vertikal tiang

\begin{tabular}{cccccccc}
\hline \hline P Tekan & SF & $\begin{array}{c}\text { P izin } \\
\text { tekan }\end{array}$ & $\begin{array}{c}\text { Cek } \\
\text { Tekan }\end{array}$ & P cabut & SF & $\begin{array}{c}\text { P izin } \\
\text { cabut }\end{array}$ & $\begin{array}{c}\text { Cek } \\
\text { cabut }\end{array}$ \\
\hline $8,574,281,933$ & 3 & 124,04 & OK & $84,134,453$ & 3 & 88,49 & OK \\
$6,868,304,609$ & 2 & 186,06 & OK & $84,023,465$ & 2 & 103,82 & OK \\
$6,861,855,481$ & 2 & 186,06 & OK & $84,104,079$ & 2 & 103,82 & OK \\
$6,134,584,414$ & 2 & 186,06 & OK & $83,993,091$ & 2 & 103,82 & OK \\
$7,320,269,093$ & 2 & 186,06 & OK & $42,014,569$ & 2 & 103,82 & OK \\
$5,981,166,974$ & 2 & 186,06 & OK & $62,101,101$ & 2 & 103,82 & OK \\
\hline \hline
\end{tabular}

- Kontrol Terhadap Gaya Lateral Tiang

Tabel 11.

Kontrol Moment Crack tiang

\begin{tabular}{cccccccc}
\hline \hline \multicolumn{8}{c}{ Kelas B PC Spun Pile D80 Waskita Precast } \\
\cline { 1 - 7 } Komb. & Faktor teg. & M crack & Hx & Hy & P max & MP & \multirow{2}{*}{ Cek } \\
\cline { 3 - 7 } & Berlebihan & ton.m & ton & ton & ton & ton.m & \\
\hline Komb. 1 & $100 \%$ & 17 & 210,77 & 0,00 & 7,03 & 10,053 & OK \\
Komb. 2 & $125 \%$ & 21,25 & 212,94 & 0,00 & 5,68 & 8,125 & OK \\
Komb. 3 & $125 \%$ & 21,25 & 210,77 & 1,05 & 5,62 & 8,043 & OK \\
Komb. 4 & $140 \%$ & 23,8 & 212,94 & 1,05 & 5,07 & 7,255 & OK \\
$\begin{array}{c}\text { Komb. } \\
\text { 5x }\end{array}$ & $150 \%$ & 25,5 & 913,65 & 156,56 & 20,60 & 24,100 & OK \\
$\begin{array}{c}\text { Komb. } \\
5 y\end{array}$ & $150 \%$ & 25,5 & 386,64 & 521,88 & 14,43 & 20,653 & OK \\
\hline \hline
\end{tabular}

- Kontrol Terhadap Gaya Horizontal Maksimum Tiang

Tabel 12.

Kontrol Gaya Horizontal Maksimum

\begin{tabular}{cccccccc}
\hline \hline \multicolumn{7}{c}{ Kelas B PC Spun Pile D80 Waskita Precast } \\
\hline \multirow{2}{*}{ Komb. } & $\begin{array}{c}\text { Faktor teg. } \\
\text { Berlebihan }\end{array}$ & $\mathbf{H x}$ & $\mathbf{H y}$ & $\begin{array}{c}\text { Hu } \\
\text { tiang }\end{array}$ & $\begin{array}{c}\text { Hu } \\
\text { Red. }\end{array}$ & $\begin{array}{c}\text { Hu } \\
\text { max }\end{array}$ & SF \\
\cline { 3 - 7 } & & ton & ton & ton & ton & ton & \\
\hline Komb. 1 & $100 \%$ & 210,77 & 0,00 & 7,026 & 7,03 & 42,560 & 6,058 \\
Komb. 2 & $125 \%$ & 212,94 & 0,00 & 7,098 & 5,68 & 42,560 & 7,495 \\
Komb. 3 & $125 \%$ & 210,77 & 1,05 & 7,026 & 5,62 & 42,560 & 7,572 \\
Komb. 4 & $140 \%$ & 212,94 & 1,05 & 7,098 & 5,07 & 42,560 & 8,394 \\
$\begin{array}{c}\text { Komb. } \\
5 x\end{array}$ & $150 \%$ & 913,65 & 156,56 & 30,899 & 20,60 & 42,560 & 2,066 \\
$\begin{array}{c}\text { Komb. } \\
5 y\end{array}$ & $150 \%$ & 386,64 & 521,88 & 21,650 & 14,43 & 42,560 & 2,949 \\
\hline \hline
\end{tabular}

J. Metode Pelaksanaan

1) Metode Pelaksanaan Tiang pancang

a. Pembersihan lahan

b. Marking titik yang akan dilakukan pemancangan

c. Pengeboran

d. Pengadaan spun pile dan peletakan spun pile kedalam galian

2) Metode Pelaksanaan Abutment

a. Pekerjaan pour abutment

- Pemasangan tulangan
- Pemasangan bekisting

- Pengecoran

b. Pekerjaan Badan dan Dinding Sayap Abutment

- Pemasangan tulangan

- Pemasangan bekisting sesuai bentuk abutment

- Pengecoran

3) Metode Pelaksanaan Geotextile wall

a. Proses persipaan dan pembersihan lahan

b. Pemasangan PVD dan PHD

c. Penempatan geotextile

d. Pemberian tanah pengisi di atas geotextile dan pemadatan

e. Diteruskan sampai ketinggian yang dikehendaki

f. Penutup permukaan dengan sheet pile

4) Metode Pelaksanaan Geogrid kombinasi Keystone-wall

a. Proses persipaan dan pembersihan lahan

b. Pembuatan pondasi telapak dangkal

c. Susun keystone wall sebagai facing

d. Penggelaran atau penghamparan material geogrid

e. Pemberian tanah pengisi diatas geogrid dan pemadatan

f. Diteruskan sampai ketinggian yang dikehendaki

\section{KESIMPULAN}

1. Perencanaan Abutmen

$\checkmark$ Dimensi abutmen yang direncanakan memiliki tinggi $4 \mathrm{~m}$, lebar $6 \mathrm{~m}$ dan panjang $20 \mathrm{~m}$.

$\checkmark$ Pondasi yang direncanakan pada abutmen ini adalah pondasi tiang pancang PC Spun Pile produk PT.Waskita Precast dengan diameter $50 \mathrm{~cm}$ yang berjumlah 52 buah dengan konfigurasi $20 \times 6$ dan kedalaman pondasi $27 \mathrm{~m}$.

$\checkmark$ Tulangan utama pada poer menggunakan D32 - 190 mm dan tulangan bagi menggunakan D20 - $300 \mathrm{~mm}$

$\checkmark$ Tulangan utama breast-wall abutmen menggunakan D32 - 300 mm dan tulangan bagi menggunakan D22$150 \mathrm{~mm}$.

$\checkmark$ Tulangan utama back-wall abutmen menggunakan D22 - 200 mm dan tulangan bagi menggunakan D19$400 \mathrm{~mm}$.

2. Pengaruh scouring dari Sungai Surabaya untuk abutment sebelah kanan jembatan joyoboyo tidak ada dikarenakan posisi letak abutment sebelah kanan jembatan joyoboyo adalah 30 meter dari penampang sungai Surabaya.

3. Waktu konsolidasi alami tanpa ada metode percepatan pemampatan adalah 134,48 tahun dengan total settlement adalah sebesar 0,64 meter.

4. Untuk mempercepat proses konsolidasi $(U v=90 \%)$ dan Mempercepat peningkatan daya dukung tanah dasar digunakan metode perbaikan tanah dasar dengan menggunakan Pre-Fabricated Vertical Drain (PVD) untuk mempercepat waktu konsolidasi.

5. Perencanaan Geotextile wall dan Geogrid retaining wall didapatkan hasil seperti ditabelkan pada Tabel 13.

Tabel 13.

Perencanaan Geotextile wall dan Geogrid retaining wall

\begin{tabular}{ccc}
\hline \hline Item Perkuatan & Geotexstile & Geogrid \\
\hline Jenis & $\begin{array}{c}\text { polypropylene } \\
\text { woven } \\
\text { geotextiles } \\
\text { Huesker } \\
\end{array}$ & \\
& Stabilenka & \\
& $200 / 45$ & \\
\hline Tipe & $200 \mathrm{KN} / \mathrm{m}$ & TT $160 \mathrm{Samp}$ \\
\hline Kekuatan Tarik & & $160 \mathrm{KN} / \mathrm{m}$ \\
\hline
\end{tabular}




\begin{tabular}{ccc}
\hline Facing & $\begin{array}{c}\text { Keystone } \\
\text { Compac IV } \\
\text { (Straight }- \\
\text { Face) }\end{array}$ & $\begin{array}{c}\text { Keystone Compac IV (Straight } \\
\text { - Face) }\end{array}$ \\
\hline Kontrol Bearing & Micropile & Micropile \\
\hline Sv & 0,5 meter & $\begin{array}{c}0,4 \text { meter; 0,6 meter dan 1 } \\
\text { meter }\end{array}$ \\
\hline Jumlah Layer & 8 layer & 7 layer \\
\hline Total Panjang & 4,5 meter & 3,5 meter \\
\hline \hline
\end{tabular}

6. Dinding penahan tanah untuk oprit direncanakan dengan membandingkan geotextile wall dan kombinasi geogrid - keystone. Pada perencanaan kombinasi geotexile wall didapatkan total biaya material yan diperlukan adalah Rp755.234.150,00 dan pada perencanaan kombinasi geogrid - keystone wall didapatkan total biaya material yang diperlukan sebesar Rp721.376.150,00 Didapatkan kesimpulan bahwa perencanaan menggunakan kombinasi geogrid - keystone merupakan perencanaan dinding penahan tanah termurah.

7. Metode pelaksanaan struktur bawah dan approach jembatan joyoboyo terdiri dari metode pelaksanaan tiang pancang, metode pelaksanaan abutment, metode pelaksanaan Geotextile wall, metode pelaksanaan geogrid kombinasi keystone-wall

\section{DAFTAR PUSTAKA}

[1] B. Supriyadi and A. S. Muntohar, Jembatan. Yogyakarta: Beta Offset, 2007. 